\title{
AS VIAGENS DO IMPERADOR: Uma abordagem inglesa para uma atuação internacional não oficial
}

\author{
Gustavo Alvim de Góes Bezerra ${ }^{1}$
}

\begin{abstract}
Resumo
Minha intenção neste artigo é discutir o impacto que as viagens pessoais, pela Europa e pela região do Mediterrâneo, do imperador Dom Pedro II tiveram na forma como o Brasil tentou se fazer enxergar, durante o segundo reinado, pelos reinos/impérios daquela região. Para tanto, utilizar-me-ei do instrumental disponibilizado pelos teóricos da Escola Inglesa, em especial Hedley Bull (1995) em The Anarchical Society.
\end{abstract}

\section{Palavras-chave}

Dom Pedro II; Europa; século XIX; Diplomacia.

\section{Abstract}

This article intends to discuss the impact that the personal trips of the Brazilian Emperor D. Pedro II through Europe and the Mediterranean had in the way that Brazil tried to be seen, throughout the second reign, by the kingdoms/empires of the region. To do so I will use the English School Theory, especially Hedley Bull (1995) in The Anarchical Society.

\section{Keywords}

Dom Pedro II; Europe; XIX century; Diplomacy.

\section{Introdução: questões teóricas e semânticas}

A fim de evitar más interpretações sobre o significado de alguns termos utilizados ou quanto à teoria instrumentalizada neste artigo, reservo esta primeira seção para algumas definições e esclarecimentos. Nas partes seguintes aprofundarei questões históricas e acontecimentos interessantes.

${ }^{1}$ Gustavo Alvim de Góes Bezerra é bacharel em Relações Internacionais pela Pontifícia Universidade Católica do Rio de Janeiro. 
Por estar ciente das diversas realidades existentes no Brasil do $2^{\underline{0}}$ reinado, não pretendo afirmar que os eventos de política externa aqui abordados e as ações do imperador afetaram a todos os rincões do território da mesma maneira, nem tenho a pretensão de afirmar que todos os lugares do Império foram afetados. Pelo contrário, para fins metodológicos, restrinjo o impacto da minha pesquisa à situação no Rio de Janeiro, ou seja, à corte imperial, onde havia uma identidade específica que não necessariamente existia em outras províncias. Portanto, sempre que me referir a "identidade", "brasileiros", "Brasil" e qualquer outro conceito que possa hoje ter um caráter mais universal, referir-me-ei à corte.

A teoria escolhida para analisar o impacto na política externa das viagens do imperador Dom Pedro II foi a Escola Inglesa, mais especificamente Hedley Bull (1995) em "The Anarchical Society: a study of order in world politics", por crer que a perspectiva de uma sociedade de Estados é mais apropriada para interpretar os impactos da atuação do imperador no exterior.

Bull (1995) diferencia de maneira muito clara dois conceitos muito importantes para a sua teoria, quais sejam: sistema de Estados e de Estados. 0 primeiro refere-se à interação entre dois ou mais Estados, ou, nas palavras do próprio autor,

A 'system of states' (or international system) is formed when two or more states have sufficient contact between them, and have sufficient contact on one another's decisions, to cause them to behave - at least in some measure - as part of the whole. (Bull, 1995) (grifo do autor)

Por sua vez, sociedade de Estados refere-se ao compartilhamento de valores entre duas ou mais nações:

A society of states (or international society) exists when a group of states, conscious certain common interests and common values form a society in the sense that they conceive themselves to be bound by a common set of rules in their relations with one another, and share in the working of common institutions. (Bull, 1995) (grifo do autor) 
No caso brasileiro, é muito fácil a aplicação desses conceitos. O Império fazia parte, inegavelmente, de um Sistema de Estados na América, em especial na América do Sul, como podem exemplificar as intervenções na região do Prata. Ou seja, o Rio de Janeiro interagia com os Estados com os quais era limítrofe. Tal espécie de contato entre atores, implícita na definição de Sistema Internacional, restringia-se ao contato entre as partes a questões de high politics, ou seja, segurança (stricto sensu) e por um viés predominantemente competitivo.

Em contrapartida, o Brasil não fazia parte de uma sociedade de Estados americanos a partir do momento em que não existem valores comuns, o que é facilmente notado ao se estabelecer a comparação entre as constituições dos recém formados países da região. 0 Brasil é único a partir do momento em que é o único império do continente (não considerando o pequeno período imperial no México de 1865 até $1867^{2}$ (Fuentes, 2001)). Assim, de acordo com a perspectiva teórica adotada, a forma de governo faz a corte participar da sociedade de Estados europeus e não americanos.

O Brasil já participava do sistema de Estados europeu mesmo antes de haver um semelhante na América. 0 seu passado colonial o havia vinculado à realidade europeia e a sua independência política não propunha o fim desse laço, pelo contrário, de certa maneira, reforçava-o porque desvinculava o país de Portugal, por meio da independência, e permite a criação (e o aprofundamento) de vínculos com outros países europeus. 0 mesmo não ocorreu com as ex-colônias espanholas que se tornaram, tão logo conseguiram suas independências, Repúblicas.

Ao contrário do que possa parecer à primeira vista, um sistema de Estados não necessita que haja fronteira entre aqueles que o compõe, a necessidade básica do sistema Sistema é a existência de contato e influência, não interessa qual a distância física entre eles.

Como já deve ter sido observado, pretendo lidar com a atuação do Estado através do imperador, não sendo de meu interesse analisar questões sociais que possam atuar no plano internacional. Dessa forma, utilizar-me-ei de conceitos que estejam relacionados à ordem internacional, aquela que trata exclusivamente dos Estados, e não me dedicarei à ordem mundial que lida com formas de interação da

2 Vale lembrar que o Imperador do México, Maximiliano, era primo-irmão de Dom Pedro II, tendo em vista que Dona Leopoldina, mulher de Dom Pedro I e mãe de Dom Pedro II, era uma Habsburgo, assim como o austríaco que regeu o México. 
sociedade que ultrapassam o Estado. A diferença conceitual fica mais bem explicada se levarmos em consideração que Bull (1995) propõe dois enfoques para o plano internacional: no primeiro, que ele chama de ordem internacional, haveria a atuação do Estado. Já a ordem mundial trata de atuação de movimentos sociais organizados sem a intervenção do Estado.

\section{Pedro de Alcântara, não Pedro II}

As viagens aqui tratadas não foram feitas com caráter oficial, pelo contrário, nos três momentos nos quais se ausenta do Império (de 25 de maio de 1871 a 5 de janeiro de 1873; de 26 de março de 1876 a 26 de setembro de 1877, e de 30 de junho de 1887 a 22 de agosto de 1888), Dom Pedro II o faz por questões pessoais, como se quisesse mesmo tirar férias.

Diversas obras ressaltam aspectos que confirmam tal perspectiva: Alexandre Delgado (1992) diz que, em Paris, gostava de ser chamado Monsieur d'Alcantara, além de andar de ônibus com a população comum. Sérgio Danese (1999) afirma que nessas viagens o imperador buscava afastar-se da política e da economia, tomar o tempo para encontros familiares (dinásticos) e enriquecimento cultural através de visitas a museus. $\mathrm{O}$ autor relata ainda o problema com a Marinha como consequência da sua recusa em utilizar um navio oficial na sua ida para Lisboa (em 1871)33, posto que não era visita oficial. Lilia Schwarcz (1998) afirma que o imperador assumia "hábitos democráticos" quando estava no exterior, comprando maçãs em praças públicas de Lisboa e rejeitando honrarias, apesar do que, aproveitava-se, por vezes, de seu título para algumas vantagens como estender o horário de bibliotecas.

Segundo Danese (1999), são completamente diferentes as análises que podem ser feitas das três viagens feitas ao exterior daquela que o imperador fez em setembro de 1865 para Uruguaiana, no Rio Grande do Sul, quando encontrou "o presidente da Argentina, Bartolomé Mitre, comandante-em-chefe das tropas aliadas na guerra contra o Paraguai, e o presidente do Uruguai, Venancio Flores" (Danese, 1999). Nesse momento, a figura representada é a figura do imperador cumprindo

3 De acordo com o conde Ludolf: "Mas se ele tivesse feito o contrário não deixariam certamente de gritar contra as despesas ocasionadas por semelhante meio de transporte, porque nada pode satisfazer quem não quer nuca estar contente". 
suas funções de chefe de Estado, participando assim do Sistema de Estados do Cone-Sul da América.

Pode-se aqui questionar quais os valores que o cidadão Pedro de Alcântara compartilha com os seus "iguais" europeus. Era imponderável ver o Sacro-Imperador Francisco José I recusando tratamento especial no porto de Lisboa, se tivesse que ficar de quarentena, pelo simples motivo de estar fazendo uma viagem não-oficial (como fizera D. Pedro II). Os valores compartilhados, que defendo eram mais amplos que detalhes como esses. 0 patriarca da monarquia brasileira era uma figura semelhante aos mais velhos das casas reais da Europa por causa de questões como sua legitimidade dinástica e o seu poder institucionalizado por uma constituição, elementos não raros entre os chefes das casas reais de então. Dessa forma, a atuação de Dom Pedro II como um "monarca-cidadão", nos termos propostos por Schwarcz (1998), não passa de uma excentricidade um tanto peculiar, que não o impedia de desfrutar da companhia das outras cabeças coroadas da Europa.

Como ressaltado por Danese (1999) no seu texto, o fato de Dom Pedro II ter se abstido de participar ativamente da diplomacia do seu tempo, no sentido de que não negociaria com as outras partes, delegando poderes para que outros o fizessem em seu lugar, possibilitou, assim, uma profissionalização da diplomacia imperial. O surgimento desses expertos foi benéfico para o Brasil que, de acordo com Danese (1999), tinha questões de política externa muito sérias para resolver no século XIX, quais sejam: o Prata, as relações desiguais com a Inglaterra e a delimitação de fronteiras.

Essa independência também pode ser vista como benéfica para o imperador, uma vez que a institucionalização impedia que sua figura se desgastasse, mas não o impedia de continuar governando, pois nunca perdera as prerrogativas de nomear os representantes brasileiros no exterior nem de instruir os negociadores brasileiros quanto aos posicionamentos que deveriam tomar sempre que fossem representar o Brasil. De acordo com Danese (1999):

Pedro II conduziu, sim, pessoalmente, a política externa do Império, com variado ânimo e intensidade, sem nunca contudo sobressaltar-se, ficando, quando muito, nos limites do que correspondia naturalmente ao enorme poder discricionário que lhe era garantido pelo sistema político do Império, para o qual, evidentemente, a política externa, mesmo tendo 
figurado em diversos momentos como prioridade máxima, estava longe de ser a espinha dorsal do poder e foco das lutas de interesse. (Danese, 1999)

O autor Zairo Cheibub (1985) também trata da organização da política externa brasileira na época do império. Nas palavras do mesmo:

Na relação com a Europa, por não envolver questões de sobrevivência do próprio Estado, prevalecia uma diplomacia rotineira, mais 'profissional', conduzida por indivíduos que começavam a constituir um grupo de diplomatas profissionais. No trato das questões com os vizinhos, porém, por envolver questões de soberania, predominava a ação política militar, conduzida por eminentes membros da elite política imperial. No final do século, esse padrão dual desaparece, prevalecendo o padrão que dominava as relações com a Europa. (Cheibub, 1985)

É dizer que as relações entre o Brasil e os seus vizinhos tinham influência direta dos quadros da política interna, enquanto que as relações com a Europa, escopo de análise deste artigo, foram em certo grau profissionalizadas, posto que não eram elementos tão delicados como os impasses fronteiriços, haja vista a situação das fronteiras do sul.

\section{Quando Pedro II foi Pedro de Alcântara}

Como foi citado acima, o monarca brasileiro deixou o Império três (longas) vezes.

A primeira vez que o fez, entre maio de 1871 e janeiro de 1873 , o fez sem apoio significativo do Parlamento, sendo que este ficou ainda mais indisposto a permitir sua ida após a descoberta de que os camarotes do navio tinham sido comprados antes da permissão oficial. Todavia, sua filha, a princesa Leopoldina de Saxe-Coburgo morre e, com a desculpa de que tem de cuidar dos netos, Dom Pedro II embarca na viagem deixando pela primeira vez a princesa Isabel como regente apoiada pelo Visconde do Rio Branco no cargo de primeiro ministro. Danese (1999) cita que as reações à viagem foram fortes e que: 
(...) muitas as especulações sobre quais os interesses reais que teriam levado o imperador a decidir-se por elas - se simplesmente a curiosidade intelectual e turística, se a incurável 'mania ambulatória' de que lhe acusavam alguns contemporâneos, se razões de saúde, se colher aplausos dos abolicionistas europeus pela evolução da questão da escravidão no Brasil, ou ainda se (...) queria ir expondo a princesa imperial ao exercício do poder e o país à idéia de ter de aceitá-la e ao Conde d'Eu, no trono, quando o Imperador viesse a falecer. (Danese, 1999)

Nesse momento não são as questões médicas as responsáveis pela viagem, tampouco era da índole do imperador "colher aplausos" por suas atuações e 'mania ambulatória' não passa de uma tentativa de ridicularizar o monarca. Resta-nos, pois, duas alternativas para análise

As curiosidades intelectual e turística são patentes na figura de Dom Pedro II. Dispensam comentários se levarmos em consideração o caráter intelectualizado do imperador. Quanto à exposição da princesa Isabel ao poder não se contradiz com a saúde do monarca estar, até então, em perfeito estado, pois Isabel era a sucessora direta do trono e tinha de estar acostumada aos imperativos do cargo quando esses surgissem. Além do que, seu pai não a havia deixado desguarnecida: tinha como primeiro-ministro um político hábil que gozava da confiança do patriarca da monarquia brasileira.

O itinerário da viagem é mais variado do que o que se esperaria de um avô preocupado com os netos que acabaram de perder a mãe. Inclui os seguintes destinos: "Portugal, Espanha, França, Inglaterra, Bélgica, Alemanha, Itália, Ásia Menor, Palestina, Egito, Itália, França, Espanha e Portugal" (Danese, 1999). O que aparenta dessa viagem é que o imperador realmente queria entrar em contato com o mundo que havia estudado por tanto tempo e do qual era um tão profundo conhecedor.

Essa viagem modificou-o.

A proximidade com o conde de Gobinau, que serviu como guia turístico, continuou quando retornaram à corte e, segundo Schwarcz (1998), o imperador queixava-se ao amigo francês evidenciando as suas decepções com a corte do Rio de Janeiro e as atribuições do seu cargo ${ }^{4}$.

${ }^{4}$ É emblemático neste contexto o fim da cerimônia do beija-mão, considerado por Dom Pedro II obsoleta. 
Teria, inclusive, declarado que preferiria ser professor a lidar com as responsabilidades do seu cargo. Gobinau era o interlocutor ideal para esse tipo de conversa uma vez que era ele mesmo um etnocentrista a quem não agradava o Brasil e os brasileiros, exceção feita ao imperador 5 . De acordo com Delgado (1992), o conde francês teria declarado: "Se ele pudesse caminhar duas léguas a pé em terras cultivadas e dormir numa granja, ficaria entusiasmado... Tenho pena que ele seja imperador... Tem demasiados talentos e méritos para isso" (Delgado, 1992).

A desilusão que Dom Pedro II, demonstrada ao retornar ao Rio de Janeiro, poder-se-ia crer, enfraquece a ideia de sociedade de Estados, contudo, não se leva em consideração que essa ideia, na verdade não se restringe ao sentimento do imperador quanto a sua capital, mas a diversas outras características que poderiam ser traçadas como comuns às duas realidades, tema que abordarei mais a fundo no último capítulo do trabalho.

Em 1876, mais especificamente, em 26 de março, o imperador parte para sua segunda viagem. Pela segunda vez na mesma década, a princesa Isabel assumirá o Estado, desta vez com Caxias como seu primeiro-ministro.

A justificativa para a viagem é a saúde da imperatriz Teresa Cristina, que será tratada na Europa após o comparecimento do casal imperial na Exposição Universal da Filadélfia, que comemora o primeiro centenário da independência dos EUA. Desta vez visitou os EUA, Canadá, Alemanha, Suécia, Finlândia, Rússia, Grécia, Ásia Menor (Turquia), Palestina, Egito, Itália, Áustria, Alemanha, França, Inglaterra, Escócia, Irlanda, Inglaterra, Holanda, Suíça e Portugal. ${ }^{6}$

O início da jornada imperial ser na América do Norte não demonstra a importância dada ao governo dos EUA, mas mostra a afeição do imperador pelas Exposições Universais. Esses eventos grandiosos eram instrumentalizados pelo império para fazer propaganda do Brasil (lato sensu) como um lugar onde havia muito exotismo, de fato, mas que era

5 Cabe ressaltar aqui dois livros escritos pelo amigo francês do Imperador: "Ensaio sobre a desigualdade das raças", de 1853, cujo título e as poucas linhas escritas sobre o autor deixam claro qual a tendência, e Les Pléiades, um romance que foi inspirado na figura de Dom Pedro e que demonstra um monarca desiludido com as suas obrigações palacianas.

${ }^{6}$ Esse foi o itinerário da viagem, por isso a repetição das citações à Alemanha e Inglaterra. 
também um império tão civilizado quanto qualquer outro Estado da Europa.

O Império brasileiro era o único Estado da América Latina a participar regularmente das Exposições ${ }^{7}$ (participamos dos eventos de 1862 em Londres; 1867, em Paris; 1873, em Viena; 1876, na Filadélfia, e 1889, em Paris), e as relações com os EUA não eram merecedoras de mais prestígio do que as relações com a Europa. Isso fica claro em um fato retratado no livro do Danese (1999), quando o então Ministro dos Negócios, Paulino Soares de Souza, fala sobre o reingresso de Carvalho Moreira na carreira diplomática e toma como primeiro posto Washington, afirma que na capital estadunidense: "o ordenado é comparativamente pequeno, péssimo o clima, e escassos os recursos, tendo-se de tratar de negócios melindrosíssimos com um governo ambicioso, astuto e poderoso". Ou seja, percebe-se, que se trata de um governo importante, poderoso, mas que tem defeitos. Não faz parte da sociedade de Estados brasileira, não compartilha valores com a corte.

Ainda assim, a passagem da comitiva imperial pelo país é marcante não só pela participação do imperador na inauguração de diversas obras públicas, e na inauguração da própria Exposição, mas também o fato de Dom Pedro II, o maior representante da única monarquia americana, ser o primeiro monarca a pisar nos EUA. Cabe ressaltar que o imperador o faz em um dos eventos comemorativos da independência dos Estados Unidos e da fundação da primeira República do continente, elementos que despertaram o interesse da população local.

Para questões pessoais essa viagem foi muito marcante para o imperador por ter lhe permitido passar mais tempo com a amante que provavelmente mais lhe marcou, a condessa de Barral. Dama de companhia da imperatriz Teresa Cristina, quando o casal imperial separa-se a condessa segue viagem com Dom Pedro e desfalca a comitiva da imperatriz que segue para os seus tratamentos medicinais em Gastein.

A terceira viagem do imperador ${ }^{8}$, desta vez por motivos de saúde próprios, ocorre já no final do império, de 30 de junho de 1887 a 22 de agosto de 1888. A princesa mais uma vez será regente, mas com a diferença de que desta vez lidará com uma troca de gabinetes. 0

${ }^{7}$ A Argentina participara de somente um desses eventos, a exposição de 1889 em Paris.

${ }^{8}$ Quem fará parte da comitiva dessa vez é o filho primogênito do Visconde do Rio Branco, José Maria da Silva Paranhos Júnior. 
primeiro-ministro com o qual se inicia a regência, o Barão de Cotegipe, cai em 10 de março de 1888 quando é substituído por João Alfredo Corrêa de Oliveira que a acompanhará até o fim do período regencial.

Desta vez, os países visitados pelo périplo imperial são: Portugal, França (para onde irá mais de uma vez, totalizando seis semanas), Alemanha, Bélgica e Itália. Comparando com as outras viagens essa demonstra não só que a idade já avançada do monarca tinha-lhe retirado a disposição para grandes turnês como também que ele realmente foi cuidar-se em Baden-Baden em uma clínica de descanso que recebera também personalidades como a rainha Vitória e Bismarck.

Dom Pedro II está realmente alheio à realidade brasileira. Não parece compreender o momento conturbado no qual está o Brasil, com a articulação de movimentos republicanos, mas, principalmente movimentos abolicionistas que mostrar-se-ão tão fortes a ponto de tornarem a situação insustentável e forçar à abolição da escravidão. Enquanto isso ocorre, Pedro de Alcântara está fazendo um cruzeiro pela Riviera italiana e demorará mais três meses para retornar ao Rio de Janeiro ${ }^{9}$. E quando o fizer já não terá apoio dos barões do café do Vale do Paraíba fluminense que foram os que mais perderam por causa da ausência de indenização pelos escravos que perderam.

Não me proponho a analisar a viagem que inicia a 18 de novembro de 1889. Questões metodológicas impedem-me de fazê-lo, posto que vejo nas viagens particulares do imperador um artifício da solidificação da sociedade de Estados com os países europeus, mas, a partir do momento em que deixa de haver aqui uma monarquia, para pára de fazer sentido a minha análise e não me proponho a analisar esta ruptura, nem tampouco, as possibilidades que então se delineiam.

\section{Dom Pedro II não, o neto de Marco Aurélio}

Em verdade, Dom Pedro II não teve nenhum avô chamado Marco Aurélio. 0 título do capítulo, que intenciona apresentar o relacionamento do imperador com intelectuais do seu tempo, é uma alusão à frase que teria sido dita por Victor Hugo ao monarca: "Sois o neto de Marco Aurélio10", mostrando sua admiração pelo imperador

${ }^{9} \mathrm{O}$ fato de ter quase morrido em Milão ao fim do cruzeiro foi um dos fatores que atrasou o seu retorno para o Rio de Janeiro.

10 Marco Aurélio foi um imperador romano nascido em 121 que morreu em 180. Governou Roma desde 161 até sua morte. Foi um estudioso de filosofia 
brasileiro. Schwarcz (1998) retrata o primeiro encontro entre o político brasileiro e o escritor francês como resultado da insistência daquele, que rompe o protocolo e vai à casa de Victor Hugo mesmo após a recusa deste em ir visitá-lo no hotel:

Ao ser introduzido pela filha do escritor, Jeanne, como a 'Majestade do Brasil', teria afirmado: 'Minha filha, aqui existe apenas uma majestade: Victor Hugo' Após a conversação é D. Pedro II que toma a iniciativa de pedir a Hugo uma foto em contrapartida lhe oferece a sua. (Schwarcz, 1998)

Imperador e intelectual, após esse encontro, passaram a corresponderse regularmente e encontrar-se sempre que o primeiro estava em Paris. Hugo teria afirmado, quando o já Pedro de Alcântara estava exilado, que o Brasil tinha feito uma besteira ao recusar um monarca que todos os Estados europeus queriam para si.

Schwarcz (1998) não analisa esse momento como o encontro entre dois intelectuais, pelo contrário, vê como um gesto político dissimulatório do imperador visando afetar os grupos republicanos brasileiros que tinham em grande estima o escritor francês. Levando-se em consideração que o relacionamento não é restrito a esse momento, questiono a validade dessa percepção.

Outro encontro sui generis foi o que ocorrera com o filósofo alemão Frederich Nietzsche, relatado por Delgado (1992). Segundo ele, Nietzsche ao entrar no trem que esperava em uma estação austríaca, dirigiu-se para a sua cabine. Percebendo que entrara no recinto errado, pede desculpas e já se retirava quando é convidado por um simpático senhor barbudo a permanecer com eles e lhes fazer companhia. 0 filósofo aceita e a partir daí entabula com o anfitrião uma longa conversa. Chegada sua estação de destino, Nietzsche, curioso sobre a pessoa com quem conversara tão longamente, informa-se e descobre que era o imperador do Brasil. Segundo Delgado (1992), a mulher do filósofo teria afirmado que esse fora um acontecimento marcante na vida do seu marido e que era um assunto recorrente nas suas conversas.

durante toda a sua vida e é tido como o último dos cinco bons imperadores romanos. É atribuído à sua morte o marco do início da decadência do império romano. 
Dom Pedro II também foi um e entusiasta das artes e ciências não só nacionalmente como também na Europa. Figuras do porte de Darwin, Pasteur e Richard Wagner estavam entre os que respeitavam o imperador, sua obra ${ }^{11}$ e esporadicamente se correspondiam com ele. 0 monarca dos trópicos chegou, como foi o caso de Wagner, a financiar alguns artistas, o que lhe propiciava vantagens como assistir à estréia de "Niebelugen"12.

Segundo Alexandre Delgado (1992), Theodore Theodor Roosevelt teria demonstrado admiração por Dom Pedro II em uma declaração que fizera a Dom Luís de Orleans e Bragança, neto do imperador brasileiro: "Não entendo como não se estabelece no Brasil uma República tendo os senhores um soberano tão filósofo, idealista e bondoso". Perceba-se que essa declaração foi feita por um futuro presidente da primeira República americana, ou seja, Dom Pedro II conseguia despertar a admiração até mesmo daqueles que não compartilhavam dos seus valores.

Essa figura ímpar que era o imperador brasileiro tinha características mesmo de intelectual. Após dominar com fluência o português, o francês, o italiano, o inglês e o alemão, o imperador tornou-se um entusiasta das línguas mortas, aprendeu assim o hebraico, sânscrito ${ }^{13} \mathrm{e}$ latim.

Dessa forma, pode-se perceber o impacto que essa figura causava na Europa quando se encontrava com intelectuais e conseguia manter com eles conversas de alto nível de refinamento muitas vezes nas suas línguas maternas natais. A imagem que se passava do Brasil não era a de um império repleto de exotismos como os povos nativos e plantas como a Vitória Régia ${ }^{14}$, passava a ser um lugar de pessoas refinadas e cultas no mesmo nível de um Estado europeu. Os valores são os mesmos, as ideas são as mesmas, a cultura, enfim, é a mesma. Afinal, foi o imperador dessas terras longínquas que financiou um dos responsáveis pela construção da identidade alemã: Richard Wagner.

\footnotetext{
${ }^{11}$ Que incluía a tradução da Bíblia e de "As Mil e Uma Noites"

12 Seres da mitologia escandinava utilizados por Wagner como ponto de partida para escrever quatro óperas que falam sobre a formação da Alemanha. ${ }_{13}$ Besouchet (1975) cita que o imperador teria pedido para o seu professor de línguas mortas ler para ele algumas páginas de sânscrito e umas notícias de jornal na noite de sua morte.

${ }^{14}$ Elemento de maior destaque no pavilhão brasileiro da Exposição Universal de Paris em 1889.
} 


\section{Quando Pedro II toma o lugar de Pedro de Alcântara}

Pode parecer contraditória, àqueles já familiarizados com os títulos, a proposta deste capítulo, cujo objetivo é abordar os momentos quando, na Europa, Dom Pedro II cumpria compromissos políticos.

A aparente contradição é, contudo, fácil de ser desfeita.

Dom Pedro de fato tinha a intenção de afastar-se da corte e da política quando se afastava do Rio de Janeiro, mas havia um fato que não lhe permitia "deixar o imperador no Brasil", como uma vez teria dito (Schwarcz, 1998): imperador não é uma profissão como qualquer outra passível de tirar férias, é um título que só se perde na morte ou na abdicação (ou em um golpe, como foi seu caso), mas uma vez perdido é difícil de ser recuperado.

Assim, estando na Europa, não lhe era possível evitar encontros com membros da realeza, do clero e políticos importantes. Era parte do protocolo e evitá-lo poderia trazer graves consequências para as suas pretensões de transformar o Brasil em uma monarquia irmã das europeias. Criticar essa postura do imperador seria repetir o mesmo erro de Eça de Queiroz ${ }^{15}$ que ironizava o fato de ao mesmo tempo em que se pretendia um "cidadão comum", não fugia dos encontros com políticos e aristocratas.

Os encontros incluíram rainha Vitória da Inglaterra; Leopoldo II da Bélgica; Francisco José I da Áustria; Ulisses Grant; Adolfo Thiers; Alexandre II da Rússia (que lhe condecorou com todas as ordens russas); o Sultão de Constantinopla, Abdul Hamid II (que lhe concedeu a Ordem de Meijidié); Kaiser Guilherme I (com quem mais tarde compartilhou um período de tratamento em Baden-Baden,) Gladstone, o rei Vittorio Emmanuele e o Papa Pio IX. Essa lista não inclui todos os encontros, trata-se apenas dos monarcas e políticos mais relevantes para a Europa de então.

\footnotetext{
$15 \mathrm{Na}$ minha pesquisa, Eça de Queiroz aparece como o único intelectual ou escritor que não era favorável à figura imperial. Chegou inclusive a escrever uma pequena brochura que ironizava a figura e de D. Pedro II e sua viagem, chamava-se "Apontamentos sobre a Picaresca Viagem do Imperador do Rasilb". Foi também esse escritor português o responsável pelo apelido Pedro da mala, uma alusão a sua valise de mão que carregava consigo quando viajava. (Schwarcz, 1999)
} 
Não levando em consideração os encontros com as cabeças coroadas da Europa, o imperador teria feito dois atos políticos de grande relevância.

0 primeiro foi durante sua primeira estadia em Paris, pouco depois do final da Guerra Franco-Prussiana. Mossé (s/d) conta em seu livro que uma banda marcial do exército prussiano fora tocar à porta do hotel no qual estava hospedado, mas que recusara a homenagem. Conta Mossé (s/d): "Se eu estivesse na Alemanha, disse ele [o imperador], não me oporia, absolutamente. Estou, porém, na França, e não posso aceitar que a música dos vencedores venha me saudar no solo dos vencidos". Pode não ter sido intencional, mas é impossível deixar de imaginar a forma como esse ato não repercutiu na sociedade parisiense de então, ao mesmo tempo em que não teriam motivos para se sentirem ofendidas as tropas germânicas.

O segundo ato é descrito por Alexandre Delgado (1992). Segundo ele, o imperador teria tentado atuar como mediador entre o rei Vittorio e o Papa Pio IX para resolver o conflito sobre Roma e a Santa Sé. Como se sabe, não obteve êxito. 0 acordo de reconhecimento mútuo só será estabelecido entre as partes em 1928 no Tratado de São João Latrão.

É interessante observar essa postura do imperador levando em consideração a crise do Império com a Igreja na década de 70 (iniciada em 1874) quando, após a negativa do Bispo de Olinda, Dom Vital, em aceitar maçons nas irmandades religiosas, ele é preso por contrariar legislação imperial ${ }^{16}$. 0 encontro foi na segunda viagem, portanto já em 1876 quando os bispos já haviam sido presos e liberados mediante acordo entre o império e a Santa Sé.

De qualquer maneira, a intenção de estabelecer o diálogo entre a Santa Sé e Roma pode ser entendido como um momento único das viagens, uma verdadeira exceção à regra, uma vez que é a busca do imperador por compromissos políticos dos quais ele quer fugir no Brasil. Todavia, não é ilógico quando percebido através da perspectiva da sociedade de Estados.

Assim o é porque além das questões referentes à monarquia (hereditariedade e constituição), o cristianismo era outro fator que

16 Durante o período imperial o imperador tinha a prerrogativa de aceitar, ou não aceitar, as determinações estabelecidas pela Santa Sé. Esse instrumento, o Padroado, era uma herança que os Bragança traziam da monarquia portuguesa e também era uma consequência da relação direta que o clero tinha com o Estado. 
coadunava as casas reais europeias. A preocupação de Pedro II com o Papa, que se dizia prisioneiro em Roma, reflete a sua identidade católica. Poder-se-ia dizer inclusive que é de tal monta importante para ele essa questão que faz com que deixe de abster-se de questões políticas para envolver-se diretamente no assunto. A lógica da sociedade de Estados fica clara em todos os encontros com os monarcas e políticos europeus: é a forma de fortalecer uma identidade comum, fortalecer os vínculos sanguíneos.

\section{Qual sociedade buscava Pedro de Alcântara?}

Para compreender em qual sociedade de Estados Dom Pedro pretendia inserir-se, é necessário traçar quais eram as similaridades que uniam a sua figura e, por conseguinte a imagem do Brasil, aos países da Europa.

Com Portugal, as afinidades eram as mais evidentes não só por ser a mesma casa real, como também se falava (e ainda hoje se fala) a mesma língua. Em paralelo a isso, não se pode ignorar a colônia portuguesa que existia na corte do Rio de Janeiro, que tivera grande importância política principalmente no reinado de D. Pedro I, sendo o evento que passou para a história como "A Noite das Garrafadas" o maior dos exemplos.

A identificação com a Áustria também era fruto de vínculos dinásticos (cabe lembrar que a mãe de D. Pedro II, a imperatriz Leopoldina era uma Habsburgo). 0 encontro entre o imperador e o seu primo, o Arquiduque Maximiliano da Áustria, em 1859, no litoral do Espírito Santo (Carvalho, 2007; Besouchet, 1975), quando este se dirigia para assumir o poder no México, demonstra a existência de uma identificação que tinha de ser mantida conforme D. Pedro fosse visitar a Europa.

As semelhanças com a França seguiam outros rumos, tendiam para uma perspectiva mais cultural, até porque quando ocorreram as viagens, a monarquia já havia sido destituída do poder no país (não só os Bourbons como Napoleão III deposto pela Guerra Franco-Prussiana e pela Comuna de Paris).

A biografia de Besouchet (1975), cuja prioridade é dar maior enfoque ao caráter cultural do imperador, e como consequência, das suas viagens, é uma excelente fonte para a captação de informações sobre a forma pela qual tal identificação era estabelecida. A principal ligação no campo da cultura deu-se pela sua incorporação como membro do 
Instituto da França, uma vez que foi através desse centro que conseguiu manter maior contato com cientistas e pensadores franceses do seu tempo. ${ }^{17}$ É o caso do seu contato com Pasteur que, apesar de não o ter conhecido no Instituto, foi através dele que conseguiu manter relações mais próximas com o sábio, a quem convidou para vir pesquisar a febre amarela no Brasil e que foi agraciado com a Comenda da Ordem da Rosa, tão logo regressou D. Pedro ao Brasil da sua primeira viagem (Carvalho, 2007).

Um grande contribuinte para a construção da imagem de similaridade com a França foi Gobinau, que se tornara amigo do imperador no tempo em que servira na missão diplomática francesa no Rio de Janeiro e que circulava com muita facilidade nos meios culturais de Paris. Era ele próprio um escritor, ainda que suas obras não fossem muito conhecidas.

Os laços pessoais com Paris foram realmente muito fortes para o imperador. Quiçá pelo seu aspecto cultural, ou pelo seu republicanismo (em seus diários afirmara mais de uma vez sua predileção pelo governo republicano), a cidade foi por ele a escolhida como destino para passar o seu exílio e seus dois últimos anos de vida, mesmo achando que Moscou era a cidade mais bonita que já tinha visto (Besouchet, 1975). ${ }^{18}$

Com os povos germânicos que começavam a formar a Alemanha tal como a conhecemos hoje os esforços de identificação não eram muitos. Não representavam destinos recorrentes nas viagens (exceção feita às águas térmicas de Baden-Baden, incluídas nos itinerários por motivos exclusivamente de saúde). Contudo, como já exposto acima, o imperador foi um dos primeiros admiradores de Richard Wagner, tendo, inclusive, contribuído para a construção do seu teatro, Bayereuth. Este compositor foi de grande importância para a construção, no imaginário coletivo, da nacionalidade alemã.

17 De acordo com Besouchet (1975), foi na saída de uma das reuniões do Instituto da França, já no exílio, que D. Pedro contraiu a pneumonia que o levaria a morte.

${ }^{18}$ As descrições sobre o funeral e as homenagens que lhe foram prestados em Paris demonstram que essa relação de carinho foi recíproca. Segundo o Daily Telegraph do dia 9 de dezembro de 1891, a multidão que observou a passagem do cortejo fúnebre do imperador, que contou com uma guarda militar de 80 mil homens para lhe prestar homenagens, só podia ser comparada à presente no enterro de Victor Hugo (Besouchet, 1975). 
Com a Rússia a sua afinidade devia-se a outro fator. Segundo Lídia Besouchet (1975), desde muito cedo D. Pedro nutria admiração por Pedro, o Grande que governou a Rússia no período de 1689 a 1725 (Hart, 2005).

Diversos traços de semelhança podem ser encontrados entre os dois monarcas além do fato de terem fundado cidades com seus nomes (São Petesburgo e Petrópolis) que se tornaram muito relevantes para a política dos países no futuro ${ }^{19}$. Ambos perderam seus pais muito cedo (Pedro, o Grande não tinha quatro anos quando seu pai morreu e D. Pedro I renunciou e fugiu para Portugal em 1831 quando D. Pedro II não tinha completado seu sexto ano). Ambos tinham grande preocupação em modernizar o sistema educacional de seus respectivos impérios ${ }^{20}$, ainda que a forma como o tzar russo o fez tenha sido direcionada para um melhor preparo do exército, e que a preocupação do imperador brasileiro tenha sido com a constituição de uma identidade nacional.

Todavia, o fato que melhor deve ter servido para ligar a imagem dos dois Pedros no imaginário russo foi o fato de o Alcântara ser um viajante. A História conta que o Pedro russo entre 1697 e 1698 viajou pela Europa para adquirir conhecimentos e descobrir tecnologias e técnicas que poderiam ser implementadas na corte russa. 0 tzar também teria tido a preocupação de ocidentalizar os modos da sua corte para aproximá-la da realidade dos Estados europeus, mesma razão que o teria levado a construir São Petersburgo (Hart, 2005). As similaridades entre os homônimos era tamanha que dizia respeito a aspectos físicos, irrelevantes para a análise política (apesar de serem

19 É importante ressaltar que apesar de o impacto das duas cidades na realidade política mundial ter sido consideravelmente diferente, no que se refere ao aspecto interno dos dois países as cidades foram concebidas para cumprir papéis semelhantes uma vez que serviam como refúgio para as elites políticas dos seus respectivos países. Apesar de nunca ter sido proclamada oficialmente a capital do Brasil, Petrópolis assumia esse status quando o imperador subia a serra para a estação de veraneio. É importante lembrar que, por se tratar de um império, a figura do monarca é determinante para definir onde é o pólo de poder, principalmente se levarmos em conta o quão centralizado era o governo na figura do monarca apesar da constituição imperial.

20 Mais de uma vez Dom Pedro II teria recomendado que fossem construídas escolas com o dinheiro que seria gasto para construir estátuas em sua homenagem. 
interessantes curiosidades), como a estatura dois, que mediam quase dois metros.

A relação com a Inglaterra da rainha Victoria é o último caso a ser estudado dentro da idea de uma sociedade de Estados europeus. A relação com esse país inclui uma perspectiva sociocultura da mesma forma que aspectos ligados ao governo e à condução de política externa.

Dom Pedro II representava não só uma figura ligada às artes e às ciências como também um mecenas de brasileiros que se interessassem em estudar no exterior. Os recursos que eram retirados da sua própria dotação anual e foram responsáveis pelo intercâmbio de mais de 120 brasileiros $^{21}$ (Carvalho, 2007), entre os quais está Pedro Américo, que ajudou a construir a imagem do império através de seus quadros. Dessa forma, Pedro II era a personificação de uma sociedade que queria modernizar-se culturalmente da mesma forma que a rainha Victoria representa um novo momento na sociedade britânica, em que na qual as artes são reavivadas e as classes médias têm uma participação maior na sociedade (Strachey, 2001). É o Reino Unido Victoriano.

Ainda é um reflexo da similaridade entre as duas sociedades a perspectiva quanto à escravidão que, como é evidente pela política externa britânica, era rechaçada por Londres e que, no Brasil, ao contrário do que diz o senso comum, havia a percepção do anacronismo que representava essa mão-de-obra no século XIX (Besouchet, 1975). É evidente que havia uma elite interessada na manutenção do escravismo, mas a Lei do Ventre-livre (1871) e antes dela o final efetivo do tráfico de escravos vindo da África (na década de 50), demonstram que a sociedade modernizava-se e conseguia avanços reais no combate à escravidão.

0 terceiro aspecto que liga a realidade brasileira à britânica é a condução de sua política externa. Ambos os países procuram outros eixos de relacionamento que não seja com os vizinhos mais próximos. No caso brasileiro, a recusa do imperador em ter relações estreitas com as repúblicas circundantes, as quais cria por serem conduzidas por caudilhos autoritários (Carvalho, 2007). No caso victoriano, a idea é expressa por meio do Isolacionismo Esplêndido, como ficou conhecida a política externa britânica do período, que representava uma recusa em

21 José Murilo de Carvalho (2007) afirma que D. Pedro II foi responsável pelos estudos do primeiro engenheiro aeronáutico do país por ter financiado um estudante de técnicas de balonismo na Europa. 
atuar no continente europeu para a resolução de problemas que não lhe dissessem respeito (Hewitt, 2006).

Pode-se questionar se a negação do Reino Unido em relacionar-se mais intimamente com os demais países europeus não enfraqueceria a própria ideia de sociedade de Estados na Europa de então. A resposta é não.

Não, por causa da característica geral que uniria os países em torno de uma sociedade: a ideia de que os laços dinásticos das casas-reais serviam como fator de aproximação que transcenderia a própria prática de Política Externa ${ }^{22}$ (Hewitt, 2006) e como elemento que permitia o reconhecimento dos seus respectivos soberanos como iguais ${ }^{23}$, Além disso, todos os Estados europeus de então reconheciam-se mutuamente como partes integrantes da civilização, sentimento que não era compartilhado necessariamente com asiáticos, americanos e africanos.

É notório que o Brasil tinha características passíveis de aproximá-lo de quaisquer países que lhe interessasse, todavia, a utilização dessas semelhanças com o intuito de aproximá-lo da Europa é o resultado de uma maior simpatia que o imperador sentia por esse continente.

\section{Conclusão: um imperador sociável}

Chego ao fim deste artigo convencido de que a sapiência do imperador Dom Pedro II lhe permitiu unir o útil ao agradável.

Era prazeroso para ele visitar a Europa. Ali era o centro de tudo o que ele representava no Brasil (governo, cultura, erudição), ao mesmo tempo em que conseguia enobrecer a imagem do país que amava junto aos que considerava iguais.

Lila Schwarcz (1998) afirma em seu livro que:

220 melhor exemplo disso é a relação da rainha Victoria com o seu tio, rei Leopold da Bélgica que insistiu que a sobrinha interviesse em assuntos que lhe eram interessantes, mas mesmo com a recusa da jovem rainha não teve impactos maiores no relacionamento dos dois (Strachey, 2001).

${ }^{23}$ De acordo com Paul Johnson, desde que Napoleão declarou-se imperador da França ele buscava ser aceito entre as outras cabeças coroadas como um igual, mas nunca o conseguiu de forma efetiva por causa da forma pela qual conseguiu o seu governo, ou seja, através da deposição de uma monarquia absolutista e legítima. 


\begin{abstract}
Em seu diário de finais da década de 80 (...) D. Pedro II escrevia: '[...] Durante minhas viagens não tive tempo senão para tornar mais conhecido o Brasil, e travar boas relações pessoais que há têm sido úteis. Se procurei mostrar aí o que já sabia, foi para que se visse que no Brasil também se estuda ainda mais em outras condições que não as minhas[...]'. (Schwarcz, 1999)
\end{abstract}

Ainda que seja muito altruísta, a passagem demonstra que Dom Pedro tinha ciência da importância que suas viagens tinham para a consolidação do Rio de Janeiro como uma corte como outra qualquer da Europa.

Além disso, é importante ressaltar que não era qualquer membro da nobreza que viajava para demonstrar aos outros as qualidades do Brasil, era sim o imperador, ou seja, a figura central do império, responsável pela manutenção da unidade social.

Esse fator passava uma mensagem ainda mais importante, qual seja: o Brasil é um império tão estável que o seu líder máximo pode dar-se ao luxo de passar mais de um ano longe das funções de Estado sem que não ocorra nenhum incidente grave. Onde na América poder-se-ia encontrar cenário semelhante? Qual líder, mesmo que europeu, poderia dar-se ao luxo de deixar o continente no qual fica seu Estado duas vezes na década de recuperação do conflito mais problemático do seu governo - a Guerra do Paraguai - na região onde a definição de fronteiras é mais complicada - o Prata. Atitudes emblemáticas que, mesmo não tendo sido intencionais (e isso será difícil de ser provado), apresentam um império que é de fato uma "ilha de tranqüilidade, um bastião de luz" (no sentido de defender os ideais europeus) em um continente de "bárbaros" (povos que não se coadunam com as perspectivas europeias).

Há de se notar também a falta das atividades características de uma corte no Rio de Janeiro. José Murilo de Carvalho (2007) retrata isso muito claramente quando fala sobre a impressão negativa que causava aos representantes de reinos estrangeiros no Brasil a ausência de atividades sociais intensas. Nas cortes europeias a atividade social era muito importante não só por questões de política interna, a partir do momento que solidifica-se a base de sustentação da monarquia, como também como atrativo para os casamentos dinásticos. 
A falta desse tipo de movimentação no Rio de Janeiro era problemática porque se unia a outros quesitos como a distância dos países europeus e a "inospitabilidade" do clima e da região para dificultar a inserção do Brasil na sociedade. Só havia uma forma de remediar essa situação: apresentando outra característica muito valorizada na Europa, a cultura. Esse foi o papel de Dom Pedro II, reverter o quadro.

Pode-se até discutir os resultados dos esforços, mas nunca a perspicácia das tentativas.

\section{Referências}

BESOUCHET, Lídia. Exílio e Morte do Imperador. Rio de Janeiro: Editora Nova Fronteira, 1975.

BOAVEnTURA, Tomás de Aquino Silveira. A Política Externa Brasileira na Concepção do Visconde do Rio Branco. Brasília. s/d Dissertação (Mestrado em História das Relações Internacionais) Instituto de Ciências Humanas - Departamento de História da Universidade de Brasília.

BRAZIL. The Empire of Brazil at the Vienna Universal Exhibition of 1873. Rio de Janeiro: E. \& H. Laemmert, 1873.

BULL, Hedley. The Anarchical Society: a study of order in world politics. New York: Columbia University Press, 1995.

CARVALHO, José Murilo de. D. Pedro II. São Paulo: Companhia das Letras, 2007.

CHEIBUB, Zairo Borges. Diplomacia e Construção Institucional: o Itamaraty em uma perspectiva histórica. Dados, v. 28, n. 1, p. 113-131, 1985.

DANESE, Sérgio França. Diplomacia Presidencial: história e crítica. Rio de Janeiro: Topbooks, 1990.

DELGADO, Alexandre Miranda. O Imperador Magnânimo: aspectos da figura de Dom Pedro II através de seus escritos e depoimentos. Rio de Janeiro: Edição do Autor, 1992.

JOHNSON, Paul. Napoleão. DUARTE, S. (Tradução). Rio de Janeiro: Objetiva, 2002. 
FAUSTO, Boris. História do Brasil. São Paulo: Editora da Universidade de São Paulo, 2006.

FUENTES, Carlos. 0 Espelho Enterrado: reflexões sobre a Espanha e o Novo Mundo. Rio de Janeiro: Rocco, 2001.

HART, Michael H. As 100 Maiores Personalidades da História.

PEREIRA, Antonio Canavarro (Tradução). Rio de Janeiro: Difel, 2005.

HEWITT, Martin. Why the Notion of Victorian Britain Does Make Sense. Victorian Studies, v. 48, n. 3, p. 395-438, 2006.

KENNEDY, Paul. Ascensão e Queda das Grandes Potências:

transformação econômica e conflito militar de 1500 a 2000. DUTRA, Waltensir (tradução). Rio de Janeiro: Elsiever, 1989.

KOSHIBA, Luiz; PEREIRA, Denise Manzi Frayze. História do Brasil: no contexto da história ocidental. São Paulo: Atual, 2003.

LEHOVICH, Dimitry V. The Testament of Peter the Grate. American Slavic and East European Review, v. 7, n. 2, p. 111-124, 1948.

LEWITTER, L. R. Peter the Great, Poland and the Westernization of Russia. Journal of the History of Ideas, v. 19, n. 4, p. 493-506, 1958.

MOSSÉ, B. Dom Pedro II: imperador do Brasil, LESSA, H.T. (Tradução). São Paulo: Edições Culturas Brasileiras, s/d.

RESIS, Albert. Russophobia and the 'Testament' of Peter the Great, 1812-1980. Slavic Review, v. 44, n. 4, p. 681-693, 1985.

SCHWARCZ, Lilia Moritz. As Barbas do Imperador: D. Pedro II, um monarca nos trópicos. São Paulo: Companhia das Letras, 1998.

STRACHEY, Lytton. Rainha Vitória. TRIGO, Luciano (tradução). Rio de Janeiro: Record, 2001. 